\title{
THE CARE OF PREMATURE INFANTS AT HOME
}

\author{
BY \\ F. J. W. MILLER, M.D., M.R.C.P., D.C.H.
}

(From the Department of Child Health, Newcastle-upon-Tyne)

It has long been apparent that an improvement in the care of premature children at home or in hospital would result in a substantial reduction in neonatal infantile mortality rates. In March, 1944, this was given official recognition in the form of a circular sent to Welfare Authorities (Ministry of Health, 1944), with recommendations for the care of premature children at home and in hospital. It was recognized that it might then be impossible for authorities to implement all the recommendations, but they were urged to do what they could. In Newcastle-upon-Tyne the matter had already been under consideration, and we decided first to make the experiment of providing adequate home care in order to have figures as a basis of comparison with institutional care and data for the guidance of future policy. The results of the care of premature infants in special hospital units are well known and have recently been described in detail by Crosse (1945), but the possibilities and the results of home care seem to have received little attention, although Brockington (1944) reported a survival rate of 66 per cent. (62 out of 94 births) for premature children attended by domiciliary midwives in the county of Warwickshire during 1943. The object of this note, therefore, is to give an account of the home care of premature infants in Newcastle-upon-Tyne from January, 1945, to May, 1946. The results will be given, and the equipment provided and the methods used will be described briefly: the special home provision was simple and excluded much that is considered essential in hospital.

\section{Results}

During the 17 months from January, 1945, to May, 1946, inclusive, 144 live premature infants were born at home. Of these, 43 received special care from one 'premature' infant nurse seconded for the purpose from the municipal midwifery service, and the remainder were nursed by the midwife or maternity nurse attending the casé. These groups cannot be directly compared, because the cases which
TABLE 1

RESULTS OF THE CARE OF ALL PREMATURE INFANTS AT HOME

(Attendance of midwife: one month if necessary)

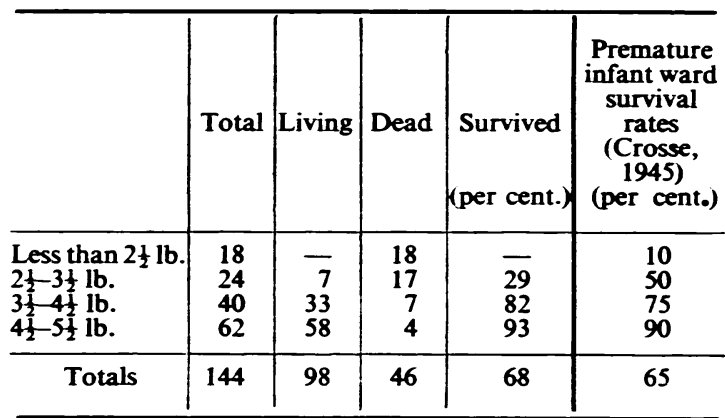

TABLE 2

RESULTS OF SPECIAL CARE AT HOME (Under conditions described)

\begin{tabular}{|c|c|c|c|c|c|}
\hline & Total & Living & Dead & $\begin{array}{c}\text { Survived } \\
\text { (per cent.) }\end{array}$ & $\begin{array}{c}\text { Premature } \\
\text { infant ward } \\
\text { survival } \\
\text { rates } \\
\text { (Crosse, } \\
1945 \text { ) } \\
\text { (per cent.) }\end{array}$ \\
\hline $\begin{array}{l}\text { Less than } 2 \frac{1}{2} \mathrm{lb} \text {. } \\
2 \frac{1}{2}-3 \frac{1}{2} \mathrm{lb} \text {. } \\
3 \frac{1}{2}-4 \frac{1}{2} \mathrm{lb} \text {. } \\
4 \frac{1}{2}-5 \frac{1}{2} \mathrm{lb} \text {. }\end{array}$ & $\begin{array}{r}2 \\
10 \\
20 \\
11\end{array}$ & $\begin{array}{r}- \\
5 \\
20 \\
11\end{array}$ & $\begin{array}{r}2 \\
5 \\
- \\
-\end{array}$ & $\begin{array}{r}\overline{50} \\
100 \\
100\end{array}$ & $\begin{array}{l}10 \\
50 \\
75 \\
90\end{array}$ \\
\hline Totals & 43 & 36 & 7 & $83 \cdot 7$ & 65 \\
\hline
\end{tabular}

received special care were not taken alternately with those which did not, and several factors of selection were present. For example, the 'premature' nurse was sometimes unable to take more cases; assistance was probably most often needed by families in the poorest circumstances; if the child was either very feeble and likely to die in an hour or two, or very lusty and likely to survive without difficulty, assistance might not be called. For these reasons, therefore, no direct comparison is possible, 
but the results of the care of all prematures will be given, and then those who received special care, and each will be compared with the survival rates of premature babies in hospital as given by Crosse (1945). The numbers are small and cover a short period of time, but they are encouraging and there is no doubt that the results of this first period can be improved.

\section{Equipment and Stafi}

Newcastle-upon-Tyne is an industrial city of 265,000 inhabitants. In the years of economic depression before 1939 the population suffered severely, and housing conditions are still very bad. Domiciliary midwifery is conducted largely by the midwives of the municipal service and the district service of the voluntary hospital, the Princess Mary Maternity Hospital, and the majority of infants are born at home (65 per cent. in 1945). The incidence of prematurity is between 6 and 7 per cent., so that 250-300 premature infants are born each year; of these, approximately 80 to 100 are born at home and the remainder in hospitals or nursing homes. There is accommodation for six premature infants in the Maternity Unit of the Newcastle General Hospital, but this is insufficient to allow the admission of infants from the district, and further accommodation is not possible without new building.

Under these circumstances, and for the reasons given above, it was decided to concentrate upon the care of infants born at home. As a beginning the following provisions were made.

Twelve sets of equipment were placed at the Newcastle General Hospital and made available on request for loan to any householder inadequately provided. Each set comprised draught-proof cot with detachable linings, hot-water bottles, mattresses, blankets, Belcroy feeders, thermometers, etc. Electric blanket pads and oxygen are not included in the equipment; the former because there is a danger of overheating the infant, and the latter because constant skilled administration is required for its use.

All the midwives of the municipal service have been given instruction concerning the care of premature infants, and as soon as staffing difficulties are eased each midwife is to be given a ' refresher' course, of at least one month, in the Premature Unit at the Newcastle General Hospital. One midwife has been seconded for the whole-time care of premature infants, and one other midwife works half time in this service. The midwife engaged primarily on the care of the infants was chosen because of her interest in the work and her experience of 23 years in midwifery practice; before starting work she was given a period of training in hospital as described above.

It has not yet been possible to arrange for a supply of breast milk for this service, but in practice it is found that the nurse is very often able to obtain milk from the mother and that very small infants are able to breast-feed satisfactorily.

The services of a home help are supplied wherever this is necessary, but it is pleasant to record that the spirit of neighbourliness and the tradition of help within the family are not yet dead in the north of England.

\section{Method of Operation}

Any medical practitioner or midwife faced with the care of a premature infant at home may call for assistance by telephoning the maternity hospital, and help is limited only by the availability of equipment and nursing staff. The equipment is sent out by hospital ambulance, which at night also picks up the nurse (during the day she uses her own car). After arrival at the home, the 'premature' nurse takes over the care of both mother and child, and the original midwife has no further responsibility in the case. The 'premature' nurse explains to the family why special attention is given to very small children, which particular dangers exist, and how she will require the co-operation of the whole family in order to do her best for the infant. Her personality is such that this co-operation is always forthcoming.

The maximum number of cases which she can care for at any given time is three; the number of visits and the length of each visit are determined by the circumstances of the case and are left to the judgement of the nurse. In some cases she has stayed all night or all day, but as a general rule either a grandmother, a member of the family, or a neighbour performs the duty of sitting with the child at night or whenever necessary during the day. Practically speaking, a maximum of three visits each day is possible: as a routine at least two visits for fourteen days, then one visit each day until the twenty-eighth day has been reached satisfactorily. The longest time the nurse has attended a case has been seven weeks. Before the 'premature' nurse stops visiting, the district health visitor takes over the supervision of the child so that there is a continuity of help available. This is made very effective by the excellent spirit of co-operation which exists between the midwives and health visitors of Newcastle.

The 'premature ' nurse is also a midwifery teacher and usually has living with her a pupil midwife who accompanies her to her cases and learns her methods of dealing with the infants. The rôle of a "premature nurse is friend, helper, and teacher; the points upon which she concentrates are feeding, warmth, standards of cleanliness, and the avoidance of infection. The results speak for themselves and are, I believe, largely a result of the nurse's personality, which brings out the best qualities of the parents and leaves a sense of accomplishment which is very good for the whole family.

\section{Financial Arrangements}

Up to the present time no charge for the loan of equipment and no extra charge beyond the fee payable for the services of a midwife has been made. 
The cost to the Authority is about twice that of the services of a midwife, as the 'premature' nurse is paid as a midwife and looks after half the number of cases when concentrating on the infants as she would do if acting as a domiciliary midwife.

\section{Conclusion}

The intention of this note has been to give the experiences of the home care of premature infants in an industrial city over a period of seventeen months. It has been written at this stage because those results have been encouraging enough to make further experience desirable, and because they will bear comparison with those obtained in premature infant units. It is no part of this note to advocate that premature infants should be born at home, but simply to state that if they are born there they should not necessarily be removed to hospital. Ultimately the best results will be obtained when premature births can be avoided or planned to take place under the best conditions.

The extension of this service would appear to be in two stages: first, to provide specialized nursing sufficient for all premature infants born at home; secondly, to train all midwives to be competent to care for these infants, so that any midwife would be able to give specialized care and attention whenever a case occurred in her own practice.

\section{REFERENCES}

Brockington, C. F. (1944). Arch. Dis. Childh., 19, 93.

Crosse, V. M. (1945). The Premature Baby. Churchill. London. P. 137.

Ministry of Health (1944). Care of Premature Infants. Circular 20. 